\title{
The effects of takeaway food and eating meals outside of the home on UK adolescents diet quality
}

\author{
A. Taher and C.E.L. Evans \\ Nutritional epidemiology group, School of Food Science and Nutrition, University of Leeds, Leeds, LS2 9JT, UK.
}

Consumption of takeaway meals and purchase of food from outside the home rather than preparation of food at home is found to be negatively associated with diet quality ${ }^{(1)}$ and positively and significantly associated with total intake of total fat, saturated fat, carbohydrates, added sugars, and sugar-sweetened beverages ${ }^{(2)}$. The aim of this project is to evaluate the association between the frequency of consuming takeaway meals and meals-out and diet quality of UK adolescents aged 11-18 years. Previous research has assessed individual macro and/or micronutrients. However, the need for higher quality data to strengthen the evidence for overall diet is required. Therefore, the diet quality index for adolescents (DQI-A) tool has been used to assess diet quality where adolescent's food intake was based on 4-Day diary records obtained from the NDNS rolling programme years 1-6. The DQI-A relies on three main components, specifically, quality, diversity and equilibrium, which reflect the degree of adherence of an adolescent diet with Food Based Dietary Guidelines (FBDG) ${ }^{(3,4)}$.

The total number of participates was 2045, and the mean age of both genders was 14.6 years. About $98 \%$ of the participants had 4-day diary records, and the overall DQI-A \% score was broadly similar across the days with no statistically significant differences between the days. Generally, the UK adolescents had a mean diet quality score of $20.4 \%$ out of $100 \%$ (ranging from $-24.2 \%$ to $67.2 \%$ ). Using self-reported frequency of consuming takeaway meals at home, respondents were categorised as low consumers (including rarely/never), moderate consumers (including once per month) and frequent consumers (including 1-2 times per week, 3-4 times per week and 5 or more times per week). Frequent, moderate and low consumption of takeaways were reported by $29.8 \%, 44.3 \%$ and $26.9 \%$ of the 2045 participants, respectively.

\begin{tabular}{|c|c|c|c|c|c|c|c|c|}
\hline \multirow[b]{2}{*}{ Frequent takeaway consumers as reference } & \multicolumn{8}{|c|}{ Adjusted analysis } \\
\hline & Low B & \multicolumn{2}{|c|}{$95 \% \mathrm{CI}$} & $\mathrm{P}$ & Moderate B & \multicolumn{2}{|c|}{$95 \% \mathrm{CI}$} & $\mathrm{p}$ \\
\hline \multicolumn{9}{|l|}{ Diet quality* } \\
\hline DQI-A Overall & $7 \cdot 4$ & $5 \cdot 5$ & $9 \cdot 2$ & $<0 \cdot 01$ & $3 \cdot 5$ & 1.9 & $5 \cdot 1$ & $<0.01$ \\
\hline Diet quality component (DQc) & $13 \cdot 6$ & $9 \cdot 7$ & $17 \cdot 5$ & $<0 \cdot 01$ & $6 \cdot 5$ & $3 \cdot 2$ & $9 \cdot 9$ & $<0 \cdot 01$ \\
\hline Diet diversity component (DDc) & $5 \cdot 1$ & $3 \cdot 5$ & $6 \cdot 7$ & $<0 \cdot 01$ & $2 \cdot 1$ & $0 \cdot 8$ & $3 \cdot 5$ & $<0 \cdot 01$ \\
\hline Diet equilibrium component (DEc) & 3.4 & $2 \cdot 4$ & $4 \cdot 4$ & $<0.01$ & 1.8 & $0 \cdot 9$ & $2 \cdot 7$ & $<0 \cdot 01$ \\
\hline Diet adequacy sub-component (DAx) & 1.9 & $0 \cdot 6$ & $3 \cdot 2$ & $<0.01$ & $0 \cdot 7$ & $-0 \cdot 5$ & 1.8 & $0 \cdot 3$ \\
\hline Diet excess sub-component (DEx) & $-1 \cdot 8$ & $-2 \cdot 7$ & $-1 \cdot 0$ & $<0.01$ & $-1 \cdot 3$ & $-2 \cdot 0$ & -0.5 & $<0.01$ \\
\hline Age (year) & $-0 \cdot 01$ & $-0 \cdot 3$ & $0 \cdot 3$ & $0 \cdot 9$ & $-0 \cdot 2$ & $-0 \cdot 4$ & $0 \cdot 1$ & $0 \cdot 2$ \\
\hline Energy (Kcal) & $-67 \cdot 0$ & $-126 \cdot 6$ & $-7 \cdot 4$ & 0.03 & $-43 \cdot 9$ & -95.4 & $7 \cdot 5$ & $0 \cdot 1$ \\
\hline
\end{tabular}

CI, Confidence Interval; DQI-A, Diet Quality Index for Adolescents.

* Scores presented as \%

Significant differences were observed between frequent (reference group), moderate and low takeaway consumers among overall DQI-A, and most of the components and sub-components $(\mathrm{p}<0.05)$, except for the diet adequacy sub-component (DAx). In conclusion, frequent consumption of takeaways is negatively associated with overall diet quality and its components. Consumption of takeaway food is common in adolescents and therefore policies to reduce availability and accessibility of fast food are needed in this age group.

1. Woodruff SJ \& Hanning RM (2009) Diet Pract Res $J$ 70, 118-24.

2. Bowman SA, Gortmaker SL, Ebbeling CB et al. (2004) Pediatrics 113, 112-8.

3. Vyncke K, Fernandez EC, Fajo-Pascual M et al. (2013) Brit J Nutr 109, 206-78.

4. Huybrechts I, Vereecken C, De Bacquer D et al. (2014) Brit J Nutr 104, 135-44. 